\title{
- A Comparative Study on the Teaching Effectiveness of Chalk \& Talk Versus Microsoft Powerpoint Presentation- An Institution Based Pilot Study of Physiotherapy Students
}

\section{Tarpan Shah' ${ }^{1}$, Megha A. Patel ${ }^{2}$, Hiral Shah ${ }^{3}$}

'Associate Vice Principal, Shree Swaminarayan Physiotherapy College, Surat, Gujarat, India, ² Physiotherapy Intern Shree Swaminarayan Physiotherapy College, Surat, Gujarat, India; '3enior Assistant Professor, Shree Swaminarayan Physiotherapy College, Surat, Gujarat, India.

\section{ABSTRACT}

Background: In traditional classrooms, a teacher's basic tools for displaying lectures are through chalkboards, pegboards, bulletin boards and walk and talk. To project instructional materials, transparencies with an overhead projector (TOHP) can be used. In recent times PowerPoint Presentation method is used as a teaching tool, it helps organize the class instructions. This aid has ability to present the information in a clear, organized \& understandable manner. So in the present study we aim to find out the best method of teaching PPT or Chalk and Talk amongst the undergraduate Physiotherapy students.

Methodology: This is a cross-sectional study of 246 students. They belonged to the age group of 18-23 years. They were recruited and the questionnaire was given. The questions were related to the effectiveness of Chalk \& Talk or PowerPoint. From this questionnaire data was collected and analysis was done.

Result: This study suggests that PowerPoint Presentation is a better teaching aid for the undergraduate students of Physiotherapy. 82.60\% students have reported PowerPoint Presentation to be a good teaching tool for learning.

Discussion: Instructors should have enough knowledge and ability about how to prepare PowerPoint presentations for appropriate paper presentation. Instructors can encourage student participation either by asking discussion questions or having the students participate in activities. Here we take Undergraduate Physiotherapy students of only one college but this sample study can be done with different colleges, fields, Postgraduate students and cities.

Conclusion: After analysis of collected data, it concludes that PowerPoint Presentation method is the effective form of lecture delivery

Key Words: Chalk \& Talk, PowerPoint Presentation, Physiotherapy students, Teaching-learning method

\section{INTRODUCTION AND BACKGROUND}

Teaching method is one of the significant components of curriculum and is an important stage of instructional design. Good teaching methods are useful tools to make helpful and meaningful learning. If teachers are familiar with different teaching methods then several useful tools are available for them to give desired content and materials to learners. Instructors in decision making to use teaching methods and select the most appropriate factors such as their expectations and the educational system expectations of learners, facilities, space, time, number of learners. Each of the methods has its own approach but the elements and their components can be used in combination, which requires good creativity, more experience and professional skills of teachers. Over the years, different approaches have been developed for teaching. ${ }^{(1)}$ Lectures can be traced long back from the Greeks of the fifth century BC, lectures were the most common form of teaching. Therefore, the lecture has its merits. Research comparing lecturing with other teaching methods has not provid-

\section{Corresponding Author:}

Tarpan Shah, Shree Swaminarayan Physiotherapy College, N.H. NO 8, Kadodara, Tal-Palsana, Dist-Surat 394327

Ph: 02622-271632, 290490; Fax-276148; Mobile: 9419013699; Email: tarpanshah@hotmail.com

ISSN: 2231-2196 (Print)

Received: 26.10 .2016
ISSN: 0975-5241 (Online)

Revised: 25.11 .2016
DOI: http://dx.doi.org/10.7324/IJCRR.2017.9118

Accepted: 02.01.2017 
ed sufficient evidence to favor one method over another. ${ }^{(2)}$

The study of Lowry had shown a marked improvement in examination results when Transparencies with an Overhead Projector (TOHP), TOHP is replaced by the PowerPoint. Therefore, there is a mixed view that emerges from current studies. In this investigation students' opinions on the impact of electronic presentations in lectures in undergraduate chemistry compared with TOHP and other conventional non-electronic approaches, and compare the impact it had on examination results. ${ }^{(3)}$

The use of PPT has become a routine affair in teaching and $99.9 \%$ teachers use it rather than any other instructional technology. ${ }^{(4)}$ Lectures presented via computerized digital presentation attract students because they provide them a different atmosphere for the study. On the other hand, they impart some advantages to lecturer as saving or updating the lecture materials. At the same time teaching with PPT enforce the learning effectiveness by stimulating student's imagery systems. ${ }^{(5)}$

The most crucial factor in the social and the economic development of a country is knowledge, which is the key requirement to prepare students to participate in an interactive society. The idea of new Information Technologies and Communication leads to changes in both the structure and the functionality of education. The Electronic learning (elearning) is more preferable than distance learning courses which offers a new dimension to the provision and content of education. Indeed, the use of new technologies of Information and Communication transforms traditional teaching and assists the adaptation of new curricula and new courses in existing applications. ${ }^{(6)} \mathrm{A}$ very interesting by-effect of the pursuit of teaching effectiveness by instructors is that this enhances their core scientific research. ${ }^{(7)}$

PowerPoint is a commonly used presentation program in business world but these days it is commonly used in the field of education. The use of PowerPoint on the basis of educational level has a supportive as well as negative impact. Proper use of PowerPoint can improve the teaching and learning experience for both staff and students. It provides support to staff by facilitating the structuring of a presentation in a proper manner. ${ }^{(8)}$

For Effective teaching learning process, the teacher must determine the process of innovations, as to identify the reform and innovation pioneers, and to examine how institutions identify problems related to teaching and learning and then make fundamental changes for better results, to explore how assessment, student diversity and the use of new technologies are incorporated into reform and innovation movements. During lecture, both the visual and auditory senses are available to absorb information and assistance in the form of a visual aid is useful. ${ }^{(9)}$ A chalkboard is uniquely ef- fective as a medium of classroom instruction and has been used commonly in the lectures, while the use of transparencies with an overhead projector is also popular. ${ }^{(10)}$ In traditional classrooms, a teacher's basic instructional tools for displaying information are chalkboards, pegboards, bulletin boards and chalk and talk. ${ }^{(11)}$ One study was done to compare PowerPoint and TOHP had shown there was no difference in student performance in exams. ${ }^{(12)}$ While in another study which shows there was marked improvement in examination results when PPT replaced the use of TOHP. ${ }^{(13)}$ So there is a mixture of views based on the recent studies and it is not clear whether the use of a particular lecture delivery method is superior to others. Therefore, this study was undertaken to find out students opinions of the impact of PowerPoint presentations in lectures compared with the traditional chalkboard teaching. ${ }^{(4)}$

\section{MATERIALS AND METHODOLOGY}

Study design: In this experimental study samples were selected by simple random sampling from students of Shree Swaminarayan Physiotherapy College and study was performed in same institution. Duration for the study was 6 months and total 246 subjects were included in the study. Exclusively only the students studying in physiotherapy belonging to age group of 18-23 years were recruited. Students not belonging to undergraduate courses, those who did not belong to physiotherapy and who were pursuing post-graduation in physiotherapy were excluded from the study. Questionnaire forms were used for collecting data.

Method: Shree Swaminarayan Physiotherapy College at Kadodara is one of the popular undergraduate women's residential teaching institutes for Physiotherapy in India. This work is based on data collected from interns of B.P.T. Students of this college belonging to each of the four years of instruction in course of 2015-16 academic year. We first circulated a questionnaire which was based on the effectiveness of teaching tools like chalk \& talk and PowerPoint. Since our objective is to compare the effectiveness of chalk \& talk and PowerPoint, we intentionally removed the option having both the teaching tools in the questionnaire and the students were asked and allowed to select only one option either chalk \& talk or PowerPoint. We instructed them to answer it based on their experience without revealing their identity. The students were invited to include specific comments or suggestions if any. We proceeded further in our study with 246 feedback questionnaire forms.

\section{RESULTS}

Out of 246 Physiotherapy students, 
- 245 voted PowerPoint as better and effective tool to explain the subject efficiently.

- 245 choose PowerPoint as more creative than chalk and talk to create interest in the subject.

- 213 choose PowerPoint as a better teaching tool to improve public speaking and presentation skills than chalk and talk.

- 103 wanted to retain chalk and talk for teaching their subject instead of replacing it with PowerPoint.

- 239 felt PowerPoint as more useful and appropriate tool for teaching than chalk and talk.

- 229 agreed and accepted PowerPoint has the basic teaching components like "Inspire, influence and inform" in a better way than chalk and talk.

- Only 24 felt PowerPoint is relatively more boring than chalk and talk.

- 218 experienced more involvement and active participation in the class when PowerPoint is used as the teaching tool.

- 239 stated that PowerPoint has most of the features needed for teaching.

- 237 recommended PowerPoint to be continued as the teaching tool.

One of the limitations of our study is that our sample is taken only from a single institution and deals with the experience of undergraduate students. It may be done in different institutions and among Postgraduate students as well.

\section{DISCUSSION}

The present study aims to compare the teaching effectiveness of chalk \& talk versus Microsoft PowerPoint presentation for the undergraduate physiotherapy students. Our study concluded that the dominant form of lecture delivery is the PowerPoint presentation method. The quality of PowerPoint presentations depends mainly on the instructor. Instructors should have enough knowledge and ability how to prepare PowerPoint presentations in terms of not only physical structure but also the content, Visuals including pictures, animations or videos related to content may be helpful to keep student attentive in lecture. According to students, clarity of words, illustrations, real pictures and summarizations were some of the attributes best deal with on PPT. PowerPoint presentations could be turned to typical teacher-centered instruction if instructors do not provide student participation by discussion, asking questions or having students participate in activities. This study can also be done with different colleges, fields, professors with various degrees $\&$ in different cities.

\section{CONCLUSION}

After analysis of the data which was collected from undergraduate students of physiotherapy, it was concluded that
PowerPoint presentation method is better than the chalk \& talk method as a teaching aid. Most of the students choose PowerPoint as a more creative tool which is effective to explain the subject efficiently, to improve public speaking and presentation skills and to teach the basic components like "inspire, influence and inform" in a better way. Because of all these features, students recommended PowerPoint to be continued as the preferred teaching tool.

\section{ETHICAL CLEARANCE}

Ethical clearance for the present study was obtained from ethical committee of Shree Swaminarayan Physiotherapy College.

\section{ACKNOWLEDGEMENT}

The author acknowledges the immense help received from the scholars whose articles are cited and included in references of this manuscript. The authors are also grateful to authors/editors/publishers of all those articles, journals and books from where the literature for this article has been reviewed and discussed. The authors are extremely grateful to IJCRR editorial board members and IJCRR team of reviewers who have helped to bring quality to this manuscript.

Source of Funding: There was no source of funding.

Conflict of Interest: There was no conflict of interest.

\section{REFERENCES}

1. Belias Dimitrios, Dr. Sdrolias Labros, Dr. Kakkos Nikolaos, Koutiva Maria, Dr. KousteliosAthanasios (2013) European Scientific Journal Edition Vol.9, No.28 ISSN: 1857-7881 (Print) e - ISSN 1857-7431, 73-101.

2. Krishna et al (2012) Comparative study on the teaching effectiveness of Chalk \& Talk and Microsoft PowerPoint presentation from the students' perspective, International Journal Pharm Science, Vol 4, Suppl 1, 191-193.

3. D. E. Shall cross and T. G. Harrison (2007) Lectures: Electronic presentations versus chalk and talk - a chemist's view, Chemistry Education Research and Practice, 8(1), 73-79.

4. P. Aranhaet al. (2013)Chalk and Talk versus PowerPoint-perception of Nursing faculty in India, American International Journal of Research in Humanities, Arts and Social Sciences, 3(2), pp. 264-267.

5. Mann, Sandi, Robinson, Andrew (2009), Boredom in the lecture theatre. British Educational Research Journal, Vol 35 (2) 243258.

6. Costas Siriopoulos, Alternatives to "chalk and talk": Active vs. passive learning - a literature review of the debate, 1-45,http:// ssm.com/abstract $=977283$.

7. Braun, R.L., \& Simpson, W.R. (2004), the pause method in undergraduate auditing: An analysis of student assessments and relative effectiveness. Advances in Accounting Education, 6, 69-85.

8. Allan M Jones (2003), the use and abuse of PowerPoint in Teaching and Learning in the Life Sciences: A Personal Overview, Bioscience education E-Journal Volume 2: November 2003. 
9. Vikas Seth, Prerna Upadhyaya, Mushtaq Ahmad and Virendra Kumar (2010), an assessment of teachers' preference for lecture delivery methods in medical education, Educational Research and Review Vol. 5 (9), pp. 533-537.

10. Sujata Biswas, Jharna Mukharjee, Salil Mondal, (2013) Impact of Electronic and Non-Electronic Teaching Methods in Medical Physiology, Indian Medical Gazette, 431-433.

11. Robert a reiser, A history of instructional design and technology :education technology research and development .June 2001, Volume 49, issue 2,pp57-67.

\section{ANNEXURE 1}

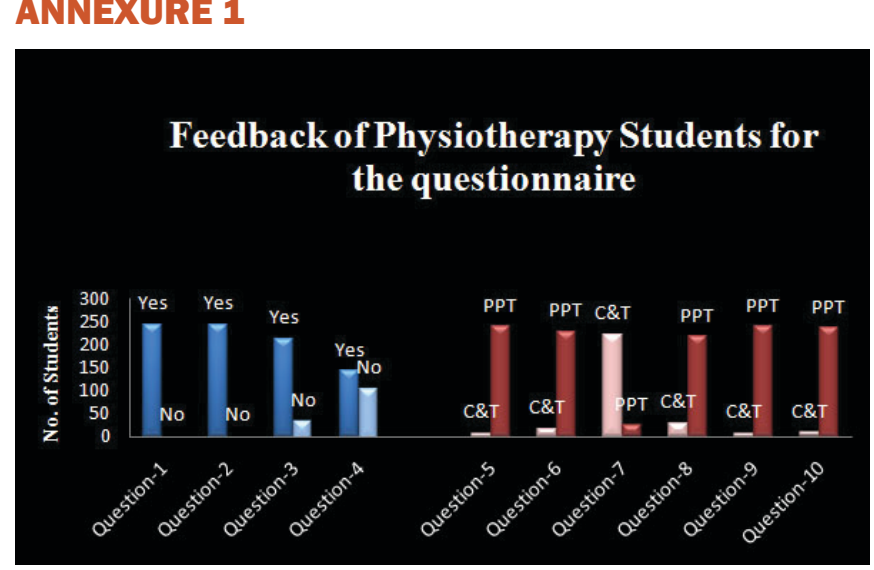

\section{ANNEXURE 2}

Shows the response of the students towards the various questions of the questionnaire

\begin{tabular}{lcc} 
& \multicolumn{2}{c}{ No. of Students } \\
& Yes & No \\
\hline Question-1 & 245 & 1 \\
Question-2 & 245 & 1 \\
Question-3 & 213 & 33 \\
Question-4 & 143 & 103 \\
& Chalk \& Talk & PowerPoint Presentation \\
Question-5 & 7 & 239 \\
Question-6 & 17 & 229 \\
Question-7 & 222 & 24 \\
Question-8 & 28 & 218 \\
Question-9 & 7 & 239 \\
Question-10 & 9 & 237 \\
\hline
\end{tabular}

